

\title{
AS UNIDADES DE PAISAGEM ENQUANTO FERRAMENTA DE DIAGNÓSTICO URBANO AMBIENTAL E ZONEAMENTO DA PAISAGEM
}

\author{
THE LANDSCAPE AS URBAN UNITS DIAGNOSTICTOOL ENVIRON- \\ MENTAL AND ZONING LANDSCAPE
}

EL PAISAJE URBANO COMO UNIDADES DE HERRAMIENTA DE DIAGNÓSTICO AMBIENTAL Y PAISAJE ZONIFICACIÓN

\author{
Nayara Amorim ${ }^{1}$ \\ Glauco Cocozza ${ }^{2}$
}

\section{Resumo}

A pesquisa tem como metodologia a identificação das Unidades de Paisagem e como objeto de estudo o perímetro urbano de Patos de Minas - Minas Gerais-Brasil. As unidades são porções territoriais da malha onde há semelhança na paisagem urbana, determinada por fatores físicos, naturais ou antrópicos. O objetivo central é evidenciar o estudo da paisagem urbana como instrumento capaz de auxiliar a compreensão, melhoria e manutenção dos valores da paisagem, gestão do sistema de espaços livres, direcionar o crescimento urbano, evidenciar os problemas ambientais urbanos, além de revelar as interações sociais e culturais, auxiliando na gestão e planejamento urbano ambiental da cidade.

Palavras-chave: Unidades de Paisagem. Morfologia Urbana. Paisagem Urbana. Sistema de Espaços Livres.

\begin{abstract}
The research has the identification methodology of Landscape Units, having as object of study the urban perimeter of Patos de Minas, a city of Minas Gerais, Brazil. The units are territorial portions of the grid where there is similarity in the urban landscape determined by physical, natural or anthropogenic factores. The central objective is to highlight the study of the urban landscape as instrument capable of aid understanding, improvement and maintenance of landscape values.
\end{abstract}

Keywords: Landscape units. Urban Morphology. Urban Landscape. Open Spaces System.

\section{Resumen}

La investigación es acercarse a la identificación de las unidades de paisaje, con el objeto de estúdio el perimeter urbano de Patos de Minas, una ciudad de Minas Gerais, Brasil. Las unidades son porciones territoriales de la cuadrícula donde existe una similitud en el paisaje urbano determinado por físicos, naturales o antropogénicos. El principal objetivo es destacar el estudio del paisaje urbano como una herramienta para ayudar a la comprensión, la mejora y el mantenimiento de los valores del paisaje, la gestión del sistema de espacios libres, revelar el crecimiento urbano, resaltar los problemas ambientales urbanos, así como revelar las interacciones sociales y culturales que ayudan en la gestión ambiental y la planificación urbana de la ciudad.

Palabras clave: Unidades de paisaje. Morfología urbana. Paisaje urbano. Sistema de los Espacios Libres. 


\section{Introdução}

O presente trabalho apresenta a forma urbana e a paisagem de Patos de Minas, uma cidade de médio porte no interior do estado de Minas Gerais - Brasil, por meio da metodologia das unidades de paisagem (U.P.s) e da análise morfológica dos elementos da paisagem. O trabalho é parte da dissertação de mestrado ${ }^{3}$ desenvolvido no Programa de Pós-Graduação em Arquitetura e Urbanismo - PPGAU da Faculdade de Arquitetura Urbanismo e Design - FAUeD - da Universidade Federal de Uberlândia.

A metodologia das Unidades de Paisagem é uma ferramenta de diagnóstico da área de estudo, um zoneamento das características morfológicas e ambientais, em que o território é dividido em zonas homogêneas, sobre as quais podem incidir diferentes diretrizes de planejamento e gestão, objetivando a organização do espaço, o uso e ocupação do solo e a valorização da paisagem.

A metodologia utilizada para delimitação das unidades na presente pesquisa consiste no cruzamento das informações de mapas temáticos que revelam um diagnóstico da área de estudo, obtido por visitas in loco, imagens aéreas do Google Earth e estudo dos aspectos socioculturais e históricos da região. $O$ trabalho apresentará essa aplicação metodológica, o processo de caracterização e problematização da cidade de Patos de Minas, desenvolvido durante os anos de 2014 e 2015, evidenciando como, a partir do diagnóstico urbano, foi obtido a delimitação das U.P.s, além da classificação e análise de cada unidade.

O trabalho faz parte da rede Quapá-SEL, (Quadro do Paisagismo - Sistemas de Espaços Livres), coordenada pelo LAB-QUAPÁ da FAUUSP (Faculdade de Arquitetura e Urbanismo da Universidade de São Paulo), cujo objetivo principal é compreender as relações processuais contemporâneas entre os sistemas de espaços livres e a forma urbana das cidades brasileiras. O trabalho aqui apresentado é também parte integrante dos estudos desenvolvidos pelo Núcleo de Estudos Urbanos (NEUrb) da FAUeD, que objetiva ampliar as investigações no campo da morfologia urbana e dos espaços livres das cidades médias da região do Triângulo Mineiro e Alto Paranaíba (MG), contribuindo, assim, com os estudos do grupo nacional Quapá-SEL.

A compreensão do conceito de paisagem urbana é o principal enfoque da pesquisa para assimilação da configuração urbana, da incorporação dos elementos do suporte físico na formação e na transformação da forma urbana e para o entendimento do papel do Sistema de Espaços Livres na cidade. A paisagem de Patos de Minas, além de caracterizar a identidade da cidade devido aos seus atributos físicos, possui um potencial paisagístico e ambiental que precisa ser incorporado ao planejamento da cidade.

Não existe um consenso sobre o conceito de paisagem, pois sua discussão transita por diversas áreas, com diferentes definições, ênfases e método de abordagem. Se-
3. Dissertação de mestrado intitulada: O Sistema de Espaços Livres na forma urbana de Patos de Minas. Projeto fomentado pela FAPEMIG, n¹1913.

4. LYNCH, K. A imagem da cidade (1960). ALEXANDER, C. Unlenguage de patrones (1980). RAPOPORT, A. Aspectos humanos de la forma urbana (1978). TUAN, Y. F. Espaço e lugar (1983) GREGOTTI, V. Nuevos caminos de La arquitectura italiana (1969). 
gundo o geógrafo Bertrand (2004), as diferenças de abordagem no conceito de paisagem são influenciadas pela formação e pelos objetivos do observador, e pode enfatizar: a vegetação, a hidrografia, o clima, o relevo, a economia, a arquitetura ou o processo histórico. A metodologia de análise poderá ser: temporal, baseada nos aspectos físicos, e se referir às relações e dinâmicas internas, ou, ainda, um conjunto de diversas análises, ou seja, a percepção individual, somada aos objetivos e ao enfoque do observador, interfere diretamente na leitura da paisagem e no seu conceito.

A partir da década de 1960, o estudo da paisagem passou a ganhar relevância entre os arquitetos. Segundo Sandeville (2006), esse processo pode ser exemplificado inicialmente pelos trabalhos de Kevin Lynch, Cristopher Alexander, Amos Rapoport, Yi Fu Tuan e Vittorio Gregotti ${ }^{4}$. De acordo com Gregotti (1983), o entendimento da paisagem é um instrumento que o arquiteto tem que ter em mãos para analisar o lugar e o espaço sobre o qual se projeta. Entretanto, a paisagem entendida só como o conjunto das características físicas e geomorfológicas, de cunho biológico e mineralógico, não é suficiente para elaboração do projeto, é preciso que a leitura da paisagem expresse as ações cotidianas, os usos dos espaços e a cultura local.

No Brasil, a arquiteta paisagista Miranda Magnoli inicia seus estudos sobre a paisagem e o ambiente na década de 1970, baseando-se nas análises estadunidenses de planejamento da paisagem e reconhecendo a importância das características socioespaciais, sem reduzir a paisagem aos aspectos formais. Segundo Magnoli (1982), a morfologia da paisagem é entendida como resultante da interação entre a lógica própria dos processos do suporte (geologia, clima, solo, relevo, vegetação e sol, água e ventos) e a lógica própria dos processos antrópicos sociais e culturais (parcelamentos, escavações, plantações, construções, edificações). As características morfológicas da paisagem conferem especificidade ao local e a configuração da paisagem (tanto os processos de suporte como os processos antrópicos) influenciam diretamente na organização, na articulação e nas tipologias de espaços livres presentes.

A paisagem retrata a forma urbana e a cultura da população, a maneira como as pessoas constroem suas casas e onde constroem; se na beira do rio, no alto das serras ou nas chapadas. É a história local contada por meio da mudança do cenário e da mudança dos padrões arquitetônicos: nas casas que permanecem do período neocolonial ou no estilo eclético, nas casas que surgiram no estilo moderno, nas reformas, nas construções que são tombadas e nas que são derrubadas. A paisagem é contada pelas árvores, pelas flores plantadas e replantadas nas calçadas; calçadas por vezes remendadas. A paisagem é o reflexo do processo social, dos bairros que se formam, das pessoas que se mudam, da economia que se desenvolve modificando o comercio, instalando novas indústrias e quem sabe até bairros industriais, gerando renda para 
O estudo da paisagem urbana e de seus aspectos morfológicos, enquanto ferramenta para delimitação de zonas homogêneas de planejamento das cidades pode ter suas origens nos estudos desenvolvidos pelo campo da morfologia urbana. Para compreender as origens conceituais das U.P.s, é preciso entender as diferentes escolas de pensamento da morfologia.

\section{As unidades de paisagem nas escolas de pensamento da morfologia urbana}

Antes de iniciar a abordagem sobre o conceito de unidades de paisagem, é preciso entender melhor as origens dessa análise e seus desdobramentos nas escolas de pensamento de morfologia urbana. É preciso entender, também, o conceito de morfologia urbana, seus elementos constituintes e sua importância para o estudo das cidades.

Segundo Del Rio (1990), a análise da morfologia urbana visa compreender a lógica de formação, evolução e transformação da cidade e de suas inter-relações, a fim de possibilitar a identificação de formas mais apropriadas, cultural e socialmente, para a intervenção urbana e o desenho de novos espaços.

Além disso, o estudo da morfologia urbana contribui para o entendimento da estrutura da cidade, sua formação e transformação, por meio de seus elementos constituintes. Segundo Lamas (2004), os elementos morfológicos são: o solo, os edifícios, o lote, o quarteirão, a fachada, o logradouro, o traçado/rua, a praça, o monumento, a vegetação e o mobiliário urbano; o autor chama de elementos morfológicos as partes físicas que associadas ou estruturadas constituem a forma urbana. Entretanto, existem diferentes análises das associações ou estruturações desses elementos morfológicos que atribuem maior importância a alguns elementos perante outros. O estudo da morfologia urbana possui três principais escolas de pensamento: a escola italiana, a francesa e a inglesa, as quais serão analisadas sinteticamente, observando suas principais características metodológicas, bases bibliográficas e formas de pensamento.

A escola italiana, segundo Mondon (1997), tem seu início nos estudos do arquiteto Saverio Muratori (1910 - 1973) e de Gianfranco Caniggia (1933 - 1987), na década de 1940. Segundo Rosaneli (2011), essa escola de pensamento possui como principal característica a preocupação com o destino das cidades históricas italianas, sobretudo devido aos efeitos das intervenções modernistas. Essa escola apresenta uma maior preocupação com o estudo tipológico das edificações (fachadas, estilos arquitetônicos, gabarito) e de suas transformações ao longo do tempo.

A escola francesa apresenta uma maior reflexão geográfica 
e historiográfica sobre as cidades e possui a contribuição do sociólogo Henri Lefebvre (1901 - 1991). Assim como a escola italiana, a escola francesa se opõe aos efeitos das intervenções modernistas. A escola francesa, segundo Rosaneli (2011), propõe uma reforma educacional no campo dos estudos urbanos e busca consolidar uma nova disciplina com duplo objetivo: primeiro, uma pesquisa descritiva multidisciplinar do espaço construído, a fim de reconhecer ingredientes de um bom desenho; e, segundo, a identificação e crítica de modelos teóricos de desenho urbano.

A escola inglesa, por sua vez, é fundamentada nos estudos do geógrafo alemão Conzen (1907 - 2000) e inicia-se na década de 1960. De acordo com Moudon (1994), a escola inglesa possui uma análise morfológica descritiva, analítica e explanatória, concentra-se no estudo da forma urbana e apresenta o mais completo, detalhado e sistemático método morfológico das três escolas.

Conzen fundamenta-se na aplicabilidade da leitura dos planos urbanos (town-plans) para o entendimento da formação urbana. De acordo com Conzen (1960 apud Rosaneli,2011), os três fundamentais elementos que compõem os planos são: as ruas que estão arranjadas em um traçado; os lotes ou parcelas individuais de terra juntamente com as quadras/quarteirões e os edifícios com seus conjuntos construídos (block-plans). As diversas combinações desses três principais elementos constituiriam unidades distintas, com "homogeneidade morfológica", o que o autor denominou de tecido urbano (plan unit, urban fabric; ou tessuto urbano para a escola italiana).

O estudo das unidades de paisagem, a ser aprofundada ainda neste trabalho, tem sua origem na escola inglesa, especificamente no conceito de regiões morfológicas ou unidades de homogeneidade morfológica desenvolvido por Conzen (1960). De acordo com Whitehand (2001), para Conzen uma região morfológica é uma área que tem uma unidade no que diz respeito à sua forma, que a distingue das áreas envolventes.

Essas unidades morfológicas, como tratadas por Cozen, e suas relações com os espaços livres de edificação, trabalhadas na pesquisa como unidades de paisagem, levantaram diversas dúvidas durante a aplicação metodológica. Como distinguir uma U.P. de outra? Que aspectos morfológicos da paisagem considerar para delimitação das unidades? O diagnóstico urbano e ambiental da área de estudo foi utilizado no trabalho como primeiro passo para responder essas questões e compreender as características de cada unidade presente na cidade. 


\section{Mapeamento da área de estudo: a cidade}

Para delimitar a área de abrangência de uma U.P. e definir as estratégias de planejamento dessa área, é preciso entender o funcionamento e organização espacial da área de estudo como um todo. Neste trabalho, o perímetro urbano de Patos de Minas, cidade média da região intermediária à Mesorregião do Triângulo Mineiro e Alto Paranaíba. Segundo o IBGE (2016), a região possuía uma população estimada de 148.762 habitantes em 2015, uma unidade territorial de $3.189,771 \mathrm{~km}^{2}$ e densidade demográfica de 43,49hab/km³.

A forma urbana patense teve seus primeiros traços no final do século XIX, às margens de uma lagoa de patos silvestres em uma planície composta por cerrado, entre o Rio Paranaíba e os Córregos do Monjolo e da Cadeia, uma terra com boa disponibilidade de recursos hídricos, propícia à agricultura. O local era um ponto de parada dos bandeirantes que buscavam as minas no interior do país rumo à cidade de Paracatu. A formação e transformação da malha urbana patense ao longo do processo histórico da região gerou na cidade áreas com características espaciais distintas, assim como ocorre nas diversas cidades brasileiras.

A pesquisa entende como U. P. porções territoriais de um dado recorte onde há semelhança entre si ou homogeneidade, determinada por características físicas, naturais e/ ou antrópicos, evidenciando padrões de distribuição de espaços livres e edificados, conforme conceituado por Silva (2012). Cada unidade possui características morfológicas próprias, como: traçado, usos, taxa de ocupação, gabarito e principalmente relações sistêmicas entre os espaços livres e os edificados. Essas características somadas ao suporte físico dão à U.P. o caráter unitário, de forma a criar zonas distintas e com características próprias no espaço urbano.

Para auxiliar o processo de entendimento da forma, da paisagem urbana e na delimitação das U.P.s de Patos de Minas foram feitas algumas análises e mapeamentos, caracterizando o suporte ambiental, a configuração espacial da malha urbana e a inserção dos espaços livres no tecido. Os enfoques analisados foram determinados com base nos elementos da paisagem urbana. Provavelmente, outro tipo de cidade, com outras características, demandaria outro segmento de análise.

Com relação ao suporte ambiental, Patos de Minas está localizada entre o Rio Paranaíba e os fundos de vale que abrigam as nascentes de alguns córregos que correm em direção ao rio. $O$ Rio Paranaíba é um elemento do suporte físico da paisagem local, limite da forma urbana em sua porção oeste. Os córregos e fundos de vale formam reentrâncias não loteadas na forma da cidade. A região possui também lagoas que se inserem na paisagem da cidade de diferentes modos, ora conectados à malha urbana, formando espaços de lazer e contemplação, ora desconectados da malha urbana e associados à esfera rural. 
A Figura 1 a seguir apresenta o levantamento das relações ecológicas presentes na forma urbana, espacializando os elementos hidrológicos, os fundos de vale e os adensamentos vegetais.

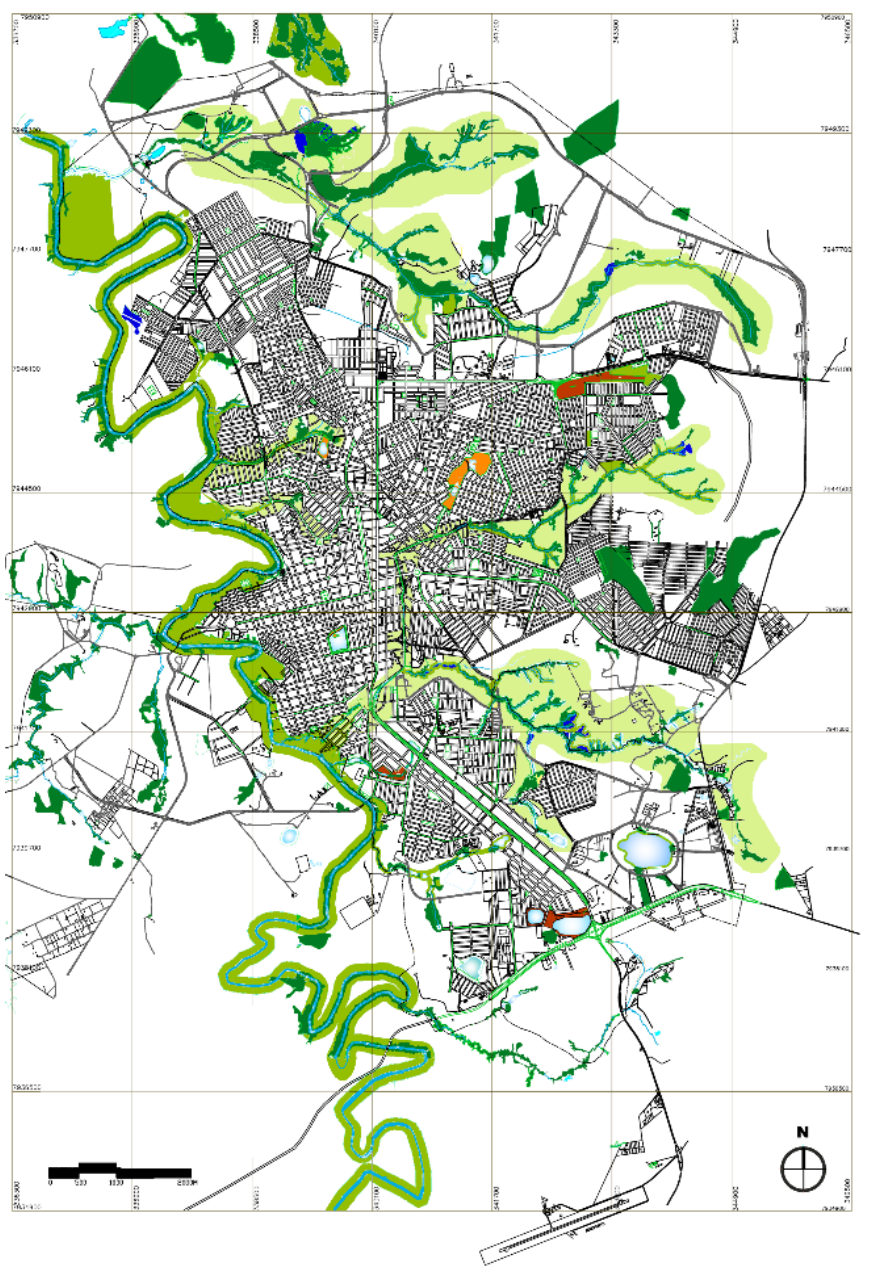

\section{LEGENDA}

- MALHA URBANA

- PROJEÇÃO DE VIAS

RIO, CÓRREGOS E LAGOAS

ÁREAS ALAGADAS
FUNDOS DE VALE

PARQUES URBANOS

PARQUES NÃO IMPLANTADOS

PRAÇAS E CANTEIROS

APP's e APA's

RESERVAS AMBIENTAIS E MATAS
Figura 1 • Relação Ecológica.

Fonte: Elaborado pelos autores. Baseado em Mapas da Prefeitura Municipal da Patos de Minas, 2015. 
Com base na Figura 1, pode-se perceber que as áreas ocupadas por fundos de vale apresentavam semelhanças morfológicas, pois contribuíram para delimitação da mancha urbana, para serem possíveis vetores de expansão da cidade, para desempenharem funções ambientais, para abrigarem atividades agropecuárias, além de caracterizarem a paisagem da cidade. Pela figura e também por visitas ao local, pode-se constatar que grande parte dos córregos incorporados à malha estão canalizados e tiveram suas áreas de proteção permanente (APP) desmatadas, são zonas de topografia acidentada, propícias a enchentes e com baixo índice de arborização. Outra questão observada é que apenas uma porção da malha urbana a oeste está conectada ao rio, essa porção é a que mais estabelece relações culturais e de subsistência com o rio.

O estudo das relações ambientais e dos atributos físicos da paisagem é importante para orientar as ações de planejamento da cidade. Em Patos de Minas, os fundos de vale têm a função de proteger as nascentes dos córregos que abastecem o Rio Paranaíba. São áreas que precisam ser protegidas, porém, podem ser incorporadas à dinâmica urbana, desempenhando funções de lazer, recreação, além de preservação ambiental.

De acordo com Ribeiro (2010), uma ocupação urbana mais adequada exige um planejamento eficiente da paisagem, que reconheça sua estrutura morfológica, identificando as saliências e reentrâncias, encostas, fundos de vale, topos, talvegues, linhas de drenagem, afloramentos rochosos, vegetação nativa, matas e reservas biológicas, cujas características ambientais devem ser condizentes aos projetos para esses espaços.

As áreas ou zonas com características semelhantes que caracterizam as U.P.s começaram a ser identificadas na Figura 1, entretanto foram necessárias mais tipologias de análises para abranger os aspectos que estruturam a cidade. Partiuse, então, para análise da configuração da malha urbana apresentado na Figura 2, espacializando o processo de consolidação do tecido urbano, evidenciando: o núcleo que deu início ao povoado, a malha urbana consolidada, a malha em processo de consolidação e os vetores de crescimento da cidade. A análise também apresenta a distribuição dos loteamentos fechados e das áreas de Habitação de Interesse Social (HIS), entendendo os mesmos como padrões morfológicos.

Ressaltando aspectos da configuração urbana, a Figura 3 evidencia a existência de um padrão na distribuição e predominância do uso do solo: residencial, comercial, industrial, de serviços e misto. 


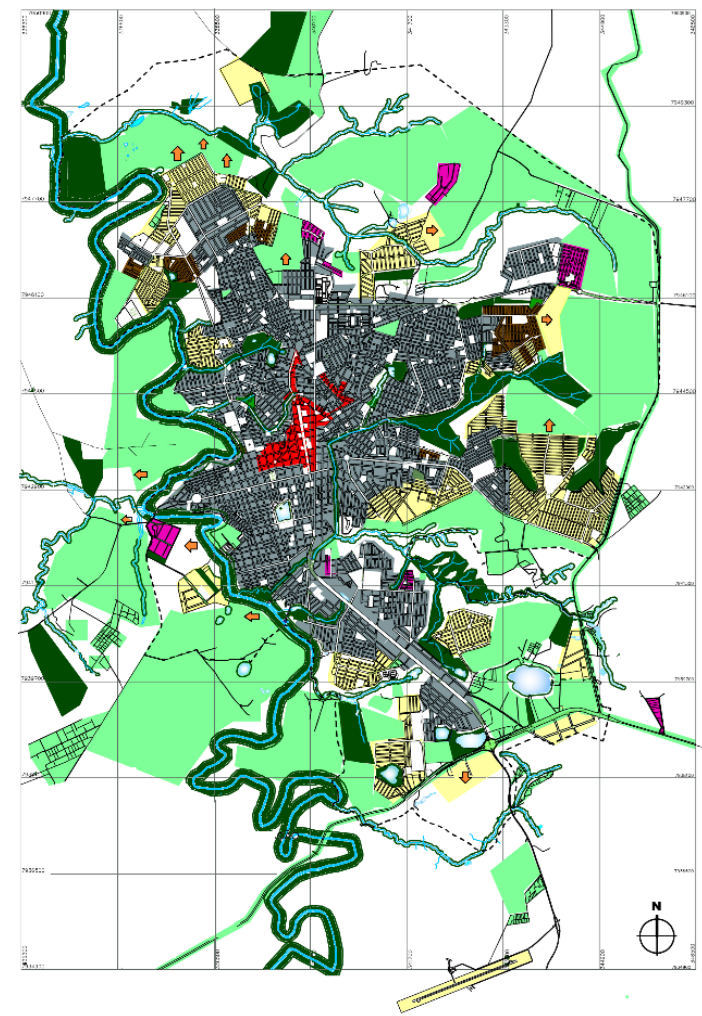

\begin{tabular}{|c|c|c|}
\hline $\begin{array}{l}\text { LEGENDA } \\
\text { INICIO DA URBANIZAÇĀO } \\
\text { MALHA URBANA CONSOUDADA } \\
\text { MALHA EM PROCESSO DE CONSOUDAÇ̄̄OO } \\
\text { LOTEAMENTO FECHADO } \\
\text { HABITAÇĀO DE INTERESSE SOCIAL } \\
\text { MEIO RURAL } \\
\text { PROTEÇĀO AMBIENTAL }\end{array}$ & $\begin{array}{l}\Rightarrow \text { VETORES DE EXPANSÃO } \\
\text { APP's } \\
\text { RIO, CORREGOS E LAGOAS } \\
\text { RERIMETRO URBANO DE } 2015 \\
\square \text { ESPAÇOS LIVRES }\end{array}$ & $\begin{array}{l}\text { LEGENDA } \\
\begin{array}{|l}\text { RESIDENCIAL } \\
\text { COMERCIAL } \\
\text { INDUSTRIAL } \\
\text { SERVIÇOS } \\
\text { MISTO }\end{array}\end{array}$ \\
\hline
\end{tabular}

Analisando as Figuras 2 e 3, pode-se perceber que a porção territorial central que corresponde ao início da urbanização é uma área de uso misto (residencial/comercial/serviços), correspondente à área mais verticalizada e à que mais concentra fluxos de pessoas e mercadorias. Grande parte da malha urbana em processo de consolidação é considerada de uso predominante residencial, e não possuem subcentros ou eixos comerciais ou de uso misto. Observa-se que a zona sul da cidade possui um eixo central de uso misto (residencial/comercial/industrial), formado por galpões, funilarias e residências, o que confere uma variação de gabaritos na paisagem.

Outro aspecto da configuração espacial patense importante de ser analisado são os tecidos urbanos que são padrões morfológicos que, vistos em conjunto, caracterizam a malha urbana e a organização espacial dos espaços livres. Os traçados se distinguem em geral por sua predominância geométrica, por sua continuidade física, padrão de desenho viário, predominância de tamanho de quadra e lote, assim como pelo suporte físico em que estão inseridos: topografia, tipo de solo, presença hídrica, arborização, clima e paisagem, dentre outros. Os tipos de traçados presentes na forma urbana patense estarão apresentados na Figura 5.
Figura 2 • Configuração urbana.

Fonte: Elaborado pelos autores. Baseado em Mapas da Prefeitura Municipal da Patos de Minas, 2015.

Figura 3 - Usos predominantes do solo.

Fonte: Elaborado pelos autores. Baseado em Mapas da Prefeitura Municipal da Patos de Minas, 2015. 
Outra análise realizada sobre o traçado urbano e seus espaços livres foi referente à inserção espacial dos mesmos na malha urbana. A Figura 6 apresenta a inserção dos espaços livres na forma urbana patense, classificados da seguinte forma:
A

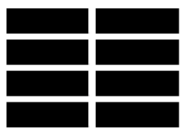

B

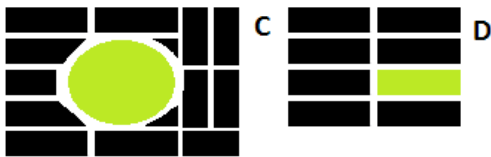

a) Espaços livres (E.L.) cuja organização espacial independe do traçado urbano;

b) Espaços livres (E.L.) que geram ou alteram o traçado;

c) Espaços livres (E.L.) inseridos no traçado;

d) Espaços livres (E.L.) formados a partir de uniões de quadras do traçado urbano;

e) Espaços livres (E.L.) formados de sobras do traçado ou do sistema viário.
5. A análise desconsidera por ora os espaços livres pertencentes ao sistema viário (ruas, becos, alamedas, avenidas, rotatórias, estradas e rodovias),

entendendo os mesmos como parte do traçado urbano.
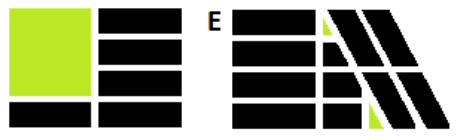

Figura 4 • Relação esquemática entre os espaços livres e o traçado urbano ${ }^{5}$.

Fonte: Elaborado pelos autores.
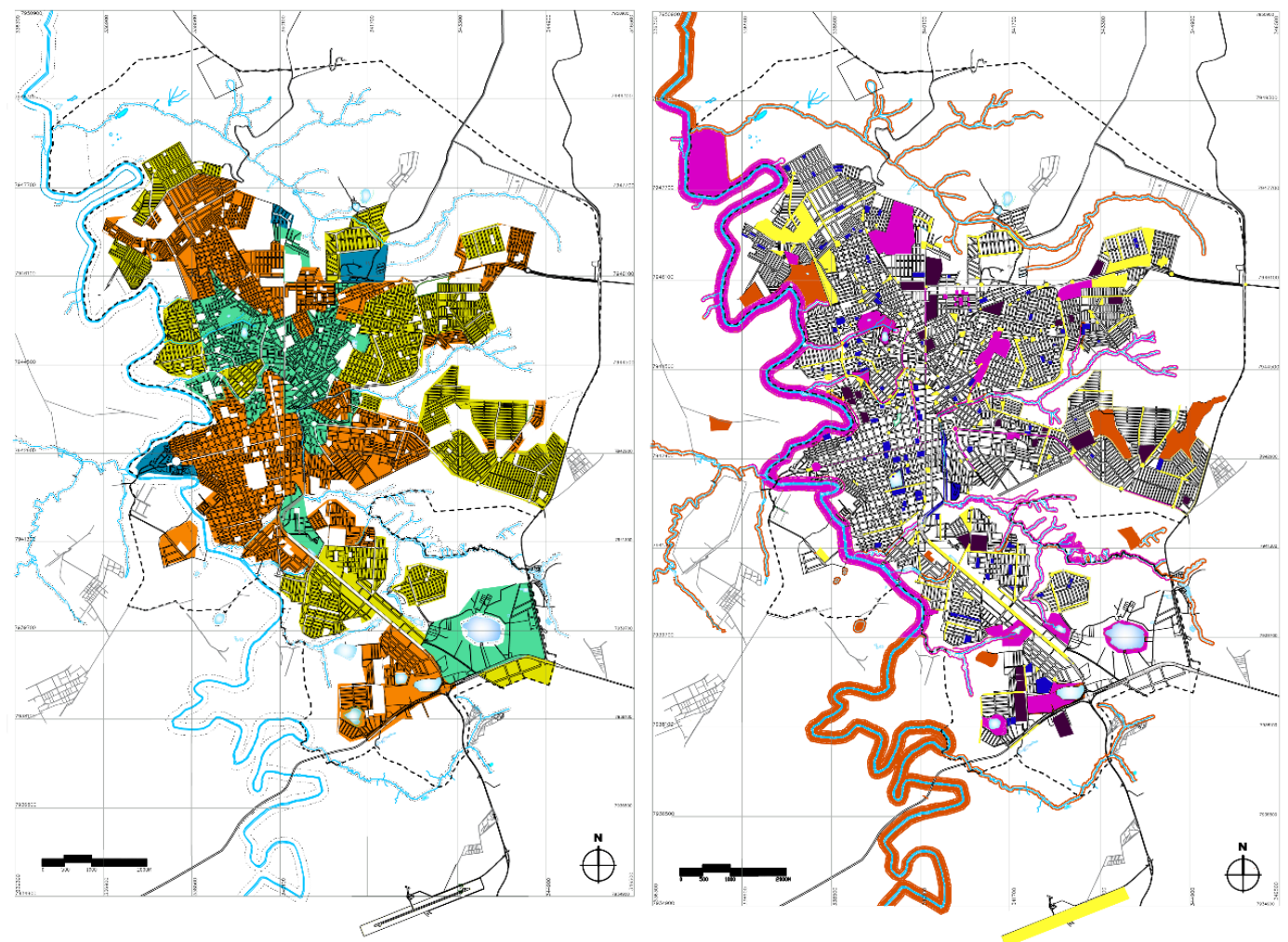

Figura 5 • Tipologias de traçado urbano.

Fonte: Elaborado pelos autores. Baseado em Mapas da Prefeitura Municipal da Patos de Minas, 2015.

Figura 6 • Espaços livres e traçado urbano.

Fonte: Elaborado pelos autores. Baseado em Mapas da Prefeitura Municipal da Patos de Minas, 2015.

Cadernos de Arquitetura e Urbanismo, v.23, n.33, 2" sem. 2016 
Com base nas Figuras 5 e 6, pode-se perceber que os principais espaços livres geradores do traçado urbano ou inibidores da presença de traçado são os corpos d'água, juntamente com suas APP's, e que se encontram em áreas de traçado urbano irregular. O traçado urbano ortogonal regular muitas vezes contribui para a padronização espacial dos espaços livres, por exemplo, lotes de tamanho regular, cuja legislação prevê a mesma porcentagem de área permeável e taxa de ocupação e que contribuem para a formação de espaços livres privados intralote homogêneos. Após o mapeamento das características ambientais, da configuração espacial urbana e de seus espaços livres, somadas às análises obtidas por meio de visitas in loco, levantamento fotográfico, imagens aéreas, conversas com moradores, pesquisas sobre manifestações populares, como festas, costumes, modos de trabalho e padrões construtivos, observouse que algumas áreas apresentaram os mesmos grupos de características morfológicas, como por exemplo: áreas da malha consolidada com traçado irregular apresentavam mais espaços livres formados a partir de sobras do sistema viário e topografia acidentada. Porções da malha em processo de consolidação, que possuem traçado ortogonal regular, espaços livres inseridos do tecido e grande parte deles não implantados, são áreas pouco inclinadas com grandes vazios e uso predominante residencial. Essas análises contribuem para caracterização da paisagem patense e identificação de possíveis zonas com características padrões morfológicos semelhantes, entendidas neste trabalho como Unidades de Paisagem.

\section{Do mapeamento das características da ci- dade a delimitação das unidades}

Foram identificados em Patos de Minas sete padrões morfológicos de configuração da paisagem (A, B, C, D, E, F e G), com base no mapeamento e análise das características da cidade. Após essa identificação, partiu-se para uma pesquisa mais detalhada de cada padrão identificado, por meio de visitas in loco, levantamento fotográfico e quantificação da dimensão das ruas, das quadras e do lote, do grau de arborização, do gabarito das edificações, da declividade e taxa de ocupação do solo. ${ }^{6}$

As visitas in loco evidenciaram, nos padrões morfológicos, algumas características divergentes, gerando subdivisões em alguns padrões morfológicos pré-identificados. A Tabela 1, a seguir, caracteriza os padrões morfológicos e suas subdivisões, que originaram as Unidades de Paisagem:
6. Os elementos morfológicos observados foram definidos e padronizados como critérios de avaliação da forma urbana pela pesquisa desenvolvida no NEUrb (Núcleo de Estudos Urbanos) - FAUeD/UFU. 


\section{Padrão morfológico identificado e sua delimitação}

\begin{tabular}{|c|c|c|c|}
\hline $\bar{A}$ & \multicolumn{2}{|c|}{$\begin{array}{l}\text { Centro comercial e de serviços da cidade. Delimitada pelo traçado } \\
\text { ortogonal irregular com alta taxa de adensamento, região mais } \\
\text { verticalizada da cidade. Presença de varias praças de pequeno } \\
\text { porte implantadas. }\end{array}$} & U.P.1 \\
\hline \multirow[t]{2}{*}{$\mathbf{B}$} & \multirow{2}{*}{$\begin{array}{l}\text { Area consolidada, traçado } \\
\text { predominantemente irregular e } \\
\text { ortogonal irregular. Delimitada pelo } \\
\text { grande adensamento e uso } \\
\text { predominantemente residencial. }\end{array}$} & $\begin{array}{l}\text { Presença de córregos } \\
\text { inseridos no tecido urbano e } \\
\text { topografia acidentada. }\end{array}$ & U.P.2 \\
\hline & & $\begin{array}{l}\text { Areas de habitação de } \\
\text { interesse social. }\end{array}$ & U.P3 \\
\hline $\mathrm{C}$ & \multicolumn{2}{|c|}{$\begin{array}{l}\text { Area urbanizada mais próxima ao Rio Paranaíba. Tecido orgánico e } \\
\text { ortogonal irregular, delimitada pela área de topografia mais } \\
\text { acidentada. Presença de ocupações irregulares na APP. }\end{array}$} & U.P.5 \\
\hline \multirow[b]{2}{*}{ D } & \multirow{2}{*}{$\begin{array}{l}\text { Areas consolidadas de traçado } \\
\text { ortogonal regular, uso predominante } \\
\text { residencial. São áreas próximas a } \\
\text { corpos d'água, porém pouco } \\
\text { conectadas a eles. }\end{array}$} & $\begin{array}{l}\text { Area consolidada pouco } \\
\text { adensada. }\end{array}$ & U.P 4 \\
\hline & & $\begin{array}{l}\text { Area em processo de } \\
\text { consolidação, vetores de } \\
\text { expansão da cidade. }\end{array}$ & U.P 6 \\
\hline E & \multicolumn{2}{|c|}{$\begin{array}{l}\text { A unidade é formada por bairros industriais, vias que concentram } \\
\text { galpões de oficinas, funilarias, empresas de ônibus e veículos } \\
\text { pesados em meio a algumas residências. Apresenta diferentes tipos } \\
\text { de uso do solo, delimitada pela variação de gabarito presente na } \\
\text { paisagem urbana. }\end{array}$} & U.P7 \\
\hline \multirow[t]{2}{*}{$\mathbf{F}$} & \multirow{2}{*}{$\begin{array}{l}\text { Ruas largas (mais de } 18 \mathrm{~m} \text { ) e lotes } \\
\text { grandes (mais de } 400 \mathrm{~m}^{2} \text { ), } \\
\text { delimitada pelo padrão construtivo. } \\
\text { Área ocupada predominantemente } \\
\text { por população de classe média- alta. } \\
\text { Presença de loteamentos fechados. }\end{array}$} & Area consolidada. & P.8 \\
\hline & & $\begin{array}{l}\text { Area em processo de } \\
\text { consolidação. }\end{array}$ & U.P.9 \\
\hline $\mathbf{G}$ & \multicolumn{2}{|c|}{$\begin{array}{l}\text { Area não consolidada, delimitada pela paisagem de transição entre } \\
\text { características urbanas e rurais, presença de córregos e fundos de } \\
\text { vale. }\end{array}$} & U.P.10 \\
\hline
\end{tabular}

Tabela 1 • Processo de delimitação das Unidades de Paisagem de Patos de Minas. 
A delimitação de unidades de paisagem, Segundo Nucci (2001), não se limita à sobreposição de mapas temáticos, pois algumas características da área de estudo estão na mente do pesquisador, que, convivendo diretamente com a realidade por meio do trabalho de campo, vai aos poucos classificando a paisagem de acordo com as características morfológicas, as quais definiu como critério. A linha de transição entre uma unidade e outra nem sempre é fácil de ser determinada, pois geralmente ela não corresponde aos limites de bairros, sendo preciso uma percepção e compreensão da paisagem que vai além da contagem dos dados levantados.

Em um primeiro momento foi feita uma delimitação a partir dos padrões morfológicos e, em seguida, uma revisão desses limites a partir das visitas aos locais para percepção espacial da paisagem. Nessas visitas foram estabelecidas conversas com os moradores para entender as relações de pertencimento com a área de entorno de suas casas. Observaramse situações em que nem os próprios moradores sabiam onde terminava um bairro e começava outro (principalmente em bairros que pertenciam a uma mesma U.P.), assim como também houve relatos de casos em que padrões construtivos diferenciavam áreas dentro de um mesmo bairro, a ponto de os moradores não as identificarem como parte de sua comunidade (partes de bairro compostas por condomínios verticais, por habitação de interesse social ou por concentração de chácaras). A transição entre as unidades foi percebida mais facilmente em áreas de diferenças drásticas de declividade, transição de tecidos urbanos, mudanças nas dimensões de vias, transição entre áreas consolidadas e em processo de consolidação e mudanças de padrões construtivos.

A delimitação das Unidades de Paisagem não é estática. O processo de urbanização da cidade pode gerar novas U.P's, incorporar novas áreas a unidades existentes, ou até mesmo uma área pode sofrer diferentes pressões (de verticalização, de adensamento, de desvalorização imobiliária), contribuindo para diferentes alterações em sua paisagem, o que pode resultar no rearranjo das unidades mapeadas.
7. Espaços livres ambaras pela legislação do CONAMA (Conselho Nacional do Meio Ambiente) 302 e 303 de 2002 e pelo Código Florestal Brasileiro.

8. Apesar do sistema viário ser um elemento da infraestrutura urbana, os espaços relacionados a ele foram agrupados separadamente (espaços livres associados a circulação), devido à complexidade das funções e usos que eles desempenham na cidade. 


\section{A caracterização de cada unidade}

A delimitação e caracterização das Unidades de Paisagem podem ser entendidas como uma proposta de organização do espaço, uma forma de zoneamento urbano, sendo alcançada por meio de uma setorização e classificação do território em setores homogêneos, em que cada área pode receber diretrizes de intervenção segundo suas características de paisagem.

A Figura 7 a seguir apresenta as dez Unidades de Paisagem identificadas em Patos de Minas:

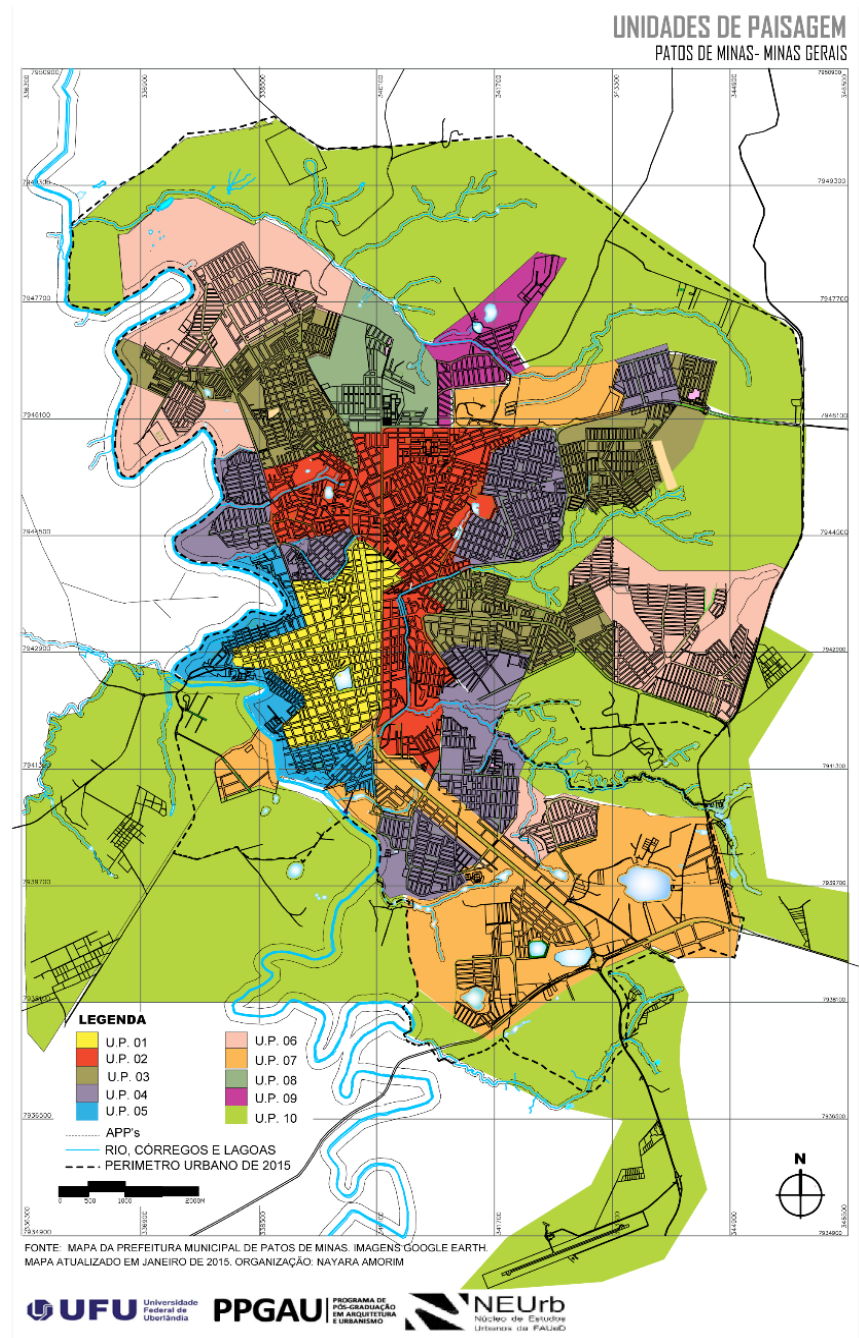

Para compreender as características da paisagem de cada unidade, a pesquisa analisou separadamente cada uma dessas zonas. A Figura 8, a seguir, apresenta como exemplo a caracterização morfológica e de paisagem da U. P. 02, mesmo processo que foi aplicado a todas unidades.

A Figura 8 apresentou a U. P. 02, que se caracteriza morfologicamente pela presença de becos e vielas (até $7 \mathrm{~m}$ de largura) e
Figura $7 \bullet$ Unidades de Paisagem de Patos de Minas.

Fonte: Elaborado pelos autores. Baseado em Mapas da Prefeitura Municipal da Patos de Minas, 2015. 


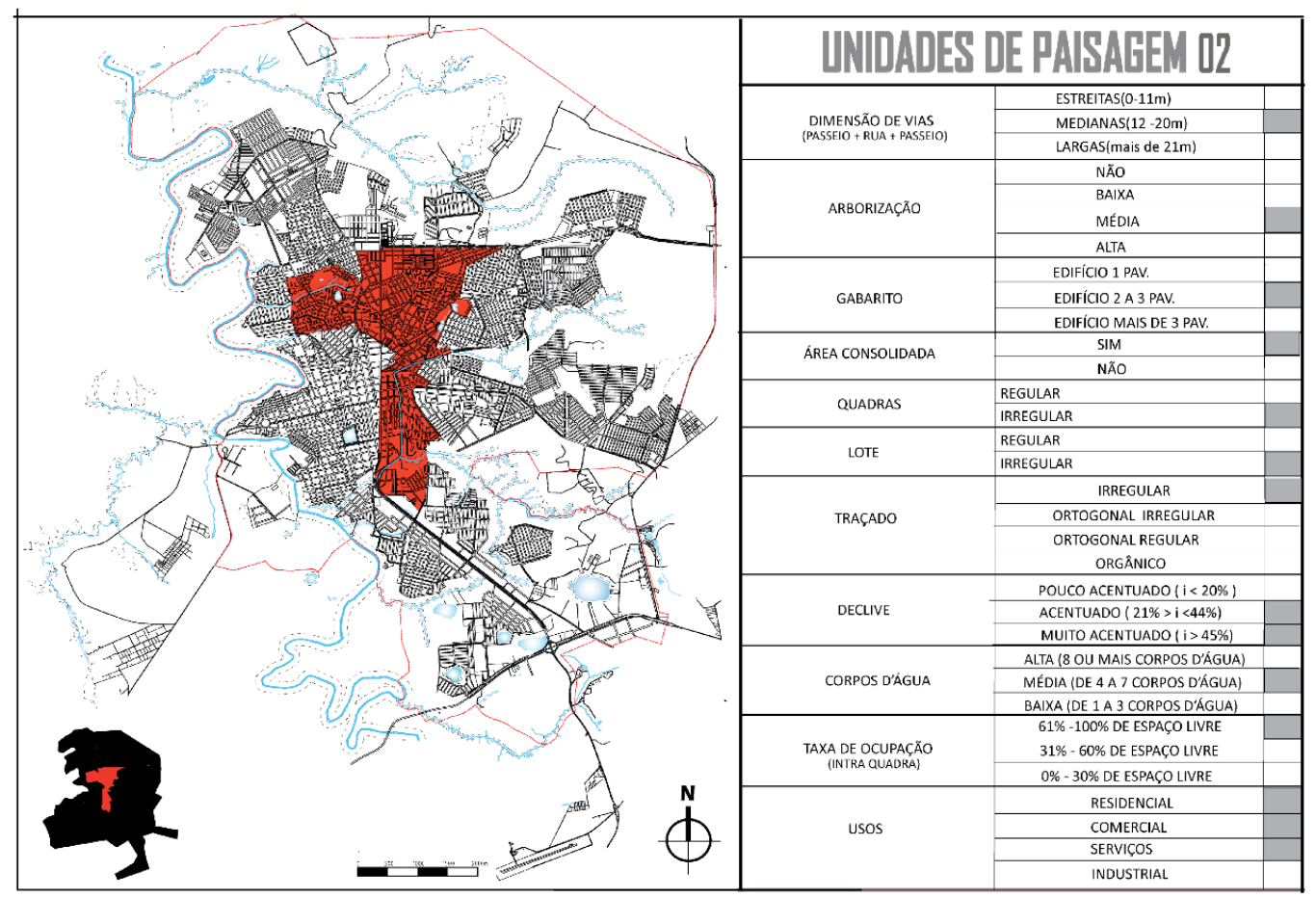

ruas de tamanho mediano (aproximadamente $13 \mathrm{~m}$ ). A presença de arborização urbana é mediana, concentrada nos parques urbanos presentes na unidade. O gabarito predominante é de até três pavimentos. É uma área consolidada que possui um traçado irregular. A declividade é acentuada, com presença alta de cursos d'água. A taxa de ocupação é mediana (31\% a $60 \%$ de espaço livre intra quadra) e o uso do solo é predominantemente misto: comercial, serviços e residencial. Essas informações foram demostradas também pelo levantamento fotográfico das unidades e por meio de desenhos esquemáticos, como na Figura 9.

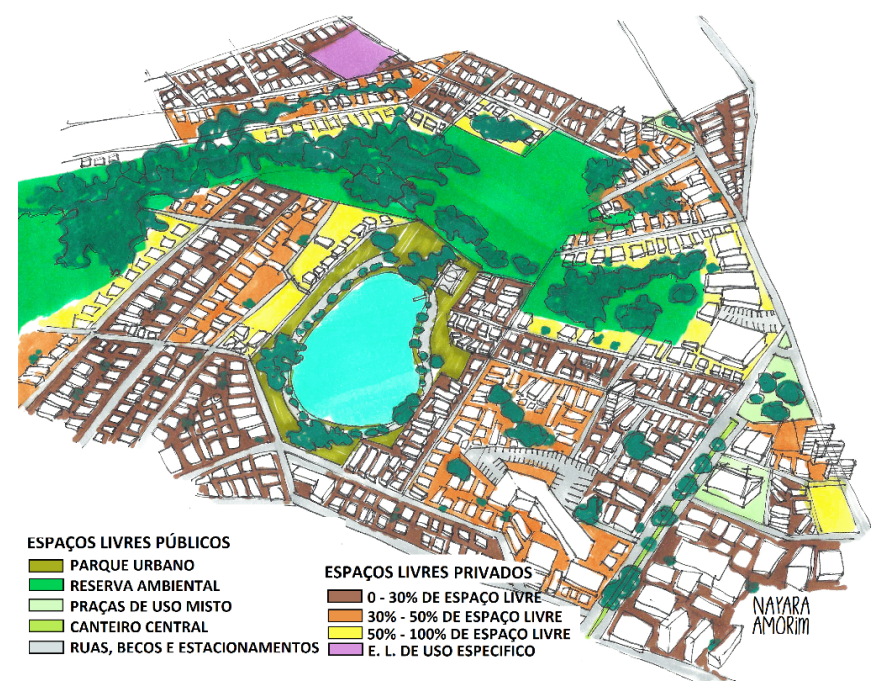

Figura 8 • Caracterização da U. P. 2.

Fonte: Elaborado pelos autores.

Figura 8 • Espaços livres de uma porção da U. P., entorno do Parque da Lagoinha.

Fonte: Desenho elaborado pela autora. 
Na U.P.2 é uma porção da cidade que abriga diversas manifestações que atraem moradores de toda cidade, principalmente na Avenida Getúlio Vargas (Figura 10), onde acontecem desfiles cívicos, manifestações políticas, festas juninas, apresentações musicais e teatrais, além das manifestações religiosas como os tapetes de Corpus Christi (Figura 11). Nessa unidade foi percebida maior relação do pertencimento e uso dos parques, como no Parque da Lagoinha e Parque do Mocambo. A U.P.2 é uma área que foi considerada borda urbana em meados de 1950, abrigando a população de renda mais baixa. Com o crescimento urbano, essa área ganhou uma característica central e grande parte desses moradores aí permaneceram.

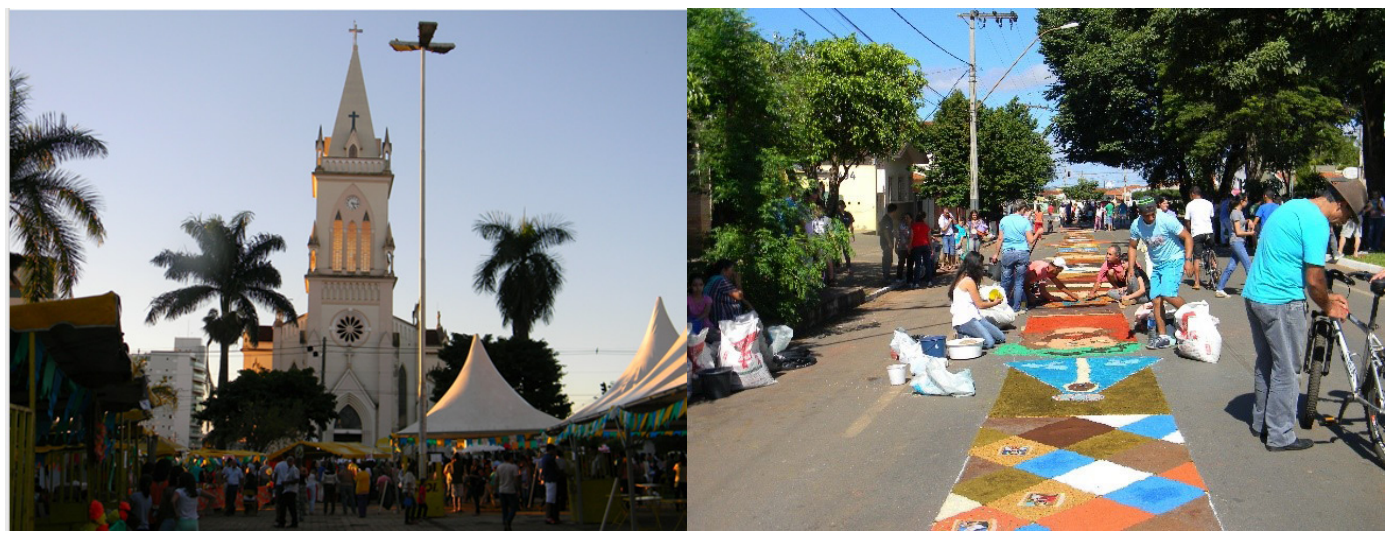

Para o estudo da presença dos espaços livres em cada Unidade de Paisagem e apontamento das potencialidades e fragilidades, foi feito um levantamento qualitativo, organizado na forma de uma tabela, cujo modelo é apresentado na Tabela 2:

\begin{tabular}{|c|c|}
\hline $\begin{array}{l}\text { Categorias de } \\
\text { Espaços Livres } \\
\text { (E.L.) }\end{array}$ & Caracterização \\
\hline $\begin{array}{l}\text { ESPAÇOS LIVRES } \\
\text { DE CARATER } \\
\text { AMBIENTAL }\end{array}$ & $\begin{array}{l}\text { Foram enumerados e analisados os espaços vinculados ao } \\
\text { suporte fisico da cidade, à hidrografia e à vegetação. São } \\
\text { espaços que têm em comum a função de proteçãa ambiental de } \\
\text { áreas verdes e ecossistemas, mas que podem ser associados a } \\
\text { outras funções como recreação, contemplação, circulação. }\end{array}$ \\
\hline $\begin{array}{l}\text { ESPAÇOS LIVRES } \\
\text { DE PRATICAS } \\
\text { SOCIAIS }\end{array}$ & $\begin{array}{l}\text { Quantificação e qualificação dos espaços destinados ao lazer, } \\
\text { ócio, esporte e recreação. }\end{array}$ \\
\hline $\begin{array}{l}\text { ESPAÇOS LIVRES } \\
\text { DE CIRCULAÇÄO }\end{array}$ & $\begin{array}{l}\text { Apontamento dos principais espaços da unidade que exercem a } \\
\text { função de circulação de pessoas, veículos e mobilidade urbana, } \\
\text { são espaços pertencentes ao sistema viário (ruas, avenidas, } \\
\text { alamedas, becos, estradas, rodovias e canteiros). }\end{array}$ \\
\hline $\begin{array}{l}\text { ESPAÇOS LIVRES } \\
\text { DE } \\
\text { INFRAESTRUTURA }\end{array}$ & $\begin{array}{l}\text { Identifica os espaços da unidade destinados a infraestrutura } \\
\text { (principalmente água, esgoto, drenagem, dejetos sólidos, } \\
\text { eletricidade e telecomunicaçôes). }\end{array}$ \\
\hline $\begin{array}{l}\text { E.L. DE SERVIÇOS E } \\
\text { ENTIDADES } \\
\text { PÜBLICAS }\end{array}$ & $\begin{array}{l}\text { São predominantemente espaços livres intralote de áreas } \\
\text { institucionais (escolas, creches, postos de saúde, prefeituras, } \\
\text { dentre outros). }\end{array}$ \\
\hline $\begin{array}{l}\text { E.L.RELACIONADOS } \\
\text { AO MEIO RURAL }\end{array}$ & $\begin{array}{l}\text { Espaços relacionados ao meio rural, localizados } \\
\text { predominantemente fora da malha urbana, apresentam funções } \\
\text { relacionadas à agropecuária. }\end{array}$ \\
\hline $\begin{array}{l}\text { POTENCIALIDADES } \\
\text { e FRAGILIDADES }\end{array}$ & $\begin{array}{l}\text { Aponta as potencialidades e as fragilidades da unidade que } \\
\text { podem gerar ações do planejamento urbano e ambiental da } \\
\text { cidade. }\end{array}$ \\
\hline
\end{tabular}

Figura 10 - Canteiro da Avenida Getúlio Vargas na festa junina, ao fundo a Igreja Matriz, 2015

Fonte: Nayara Amorim.

Figura $11 \bullet$ Tapete de Corpus Christi sendo feito pela população, 2015.

Fonte: Nayara Amorim
Tabela 2 • Categorias de espaços livres presentes nas unidades de Patos de Minas.

Fonte: Elaborado pelos autores. 
Os espaços livres identificados na cidade foram agrupados em categorias. A definição e a denominação das categorias foram elaboradas com base nos dados do NEURB-FAUeD/ UFU, na Tabela Única elaborada pelo Quapá-SEL (ORG. CAMPOS, etc.... 2012 p.230-231) e nas Tabelas de Categorias de Espaços Livres do Grupo SEL-RJ (ORG. CAMPOS, etc.... 2012 p.232-239). Esses estudos que apresentam e classificam diversos tipos de espaços livres identificados nas cidades brasileiras. No presente trabalho, selecionou-se das tabelas, que basearam o estudo, apenas as tipologias de espaços livres que foram identificados em Patos de Minas.

A distribuição espacial dos espaços livres em cada unidade foi evidenciada por desenhos representativos, como exemplificado na Figura 12 que tem como exemplo a U.P.2.

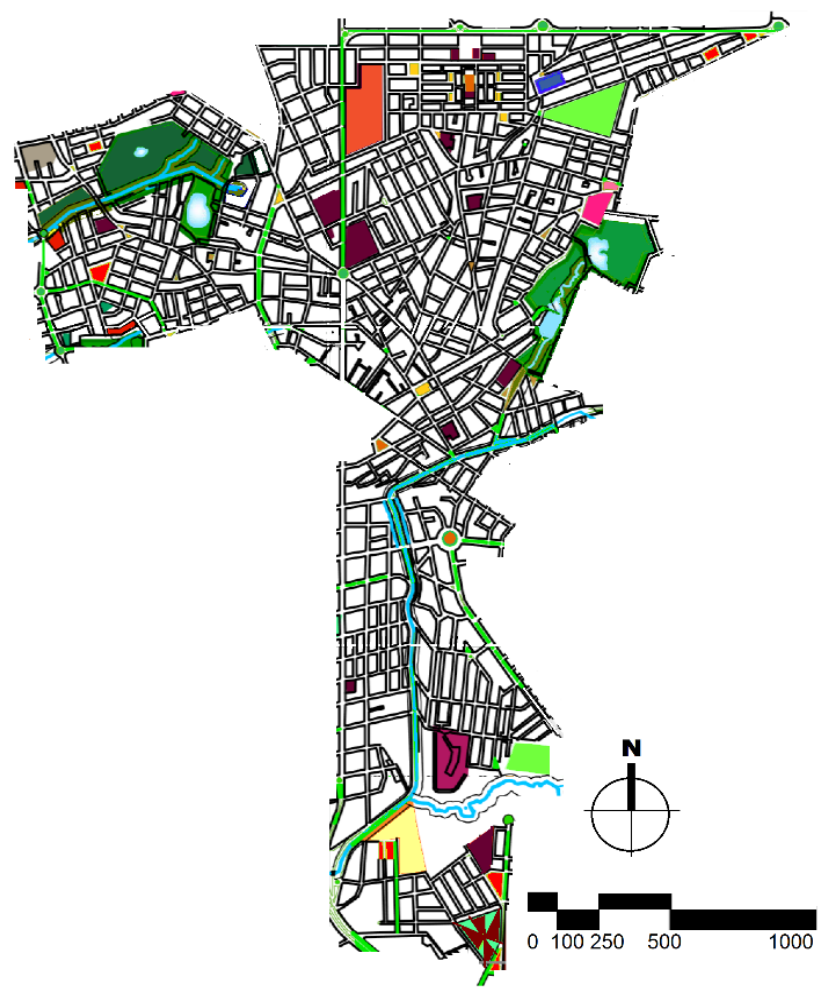

A identificação das características e, principalmente, o levantamento das potencialidades e fragilidades de uma determinada Unidade de Paisagem podem orientar as ações de planejamento urbano e ambiental. De acordo com Silva (2012), as Unidades de Paisagem carregam uma leitura especifica que revela a forma urbana existente e suas tendências, possibilitando identificar os graus de impactos: da gestão, dos programas e ações públicas e dos efeitos da transformação da paisagem. Quando o autor ressalta as tendências da forma urbana, faz menção às dinâmicas de transformação urbana, como por exemplo, os vetores de expansão urbana, a intenção de parcelar uma gleba, a tendência de verticalização de uma área induzida por uma determinada legislação urbana e a possibilidade de implantação de parques urbanos.
CATEGORIAS DE ESPAÇOS LIVRES PRESENTES NA UNIDADE DE PAISAGEM 02

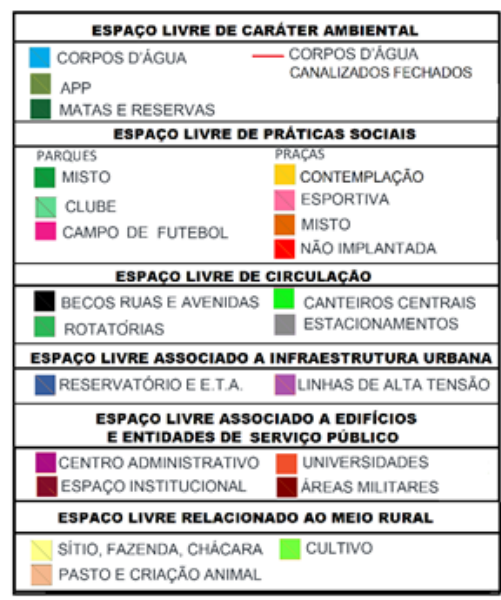

Figura 12 • Espaços Livres da U. P. 02.

Fonte: Elaborado pelos autores.

Cadernos de Arquitetura e Urbanismo, v.23, n.33, $2^{0}$ sem. 2016 
O entendimento da dinâmica urbana, dos processos socioespaciais e das características da paisagem são elementos da metodologia de análise urbana por meio das Unidades de Paisagem, a fim de identificar os valores e atributos da paisagem urbana que precisam ser requalificados, preservados ou reestruturados. A delimitação e a caracterização de cada unidade são fatores determinantes para eleger um direcionamento ao processo de transformação específico para cada área, sem perder o entendimento da estrutura urbana como um todo.

\section{Considerações Finais}

O trabalho visa contribuir com o planejamento da cidade ressaltando os atributos da paisagem e do sistema de espaços livres que precisam ser valorizados e incorporados à gestão da cidade. Em Patos de Minas, o potencial paisagístico e ambiental de elementos da paisagem, como o sistema hidrológico, o relevo e a vegetação, são elementos que poucas vezes são incorporados à dinâmica urbana com as funções de lazer, recreação e conscientização ambiental, e constituintes do SEL e de identidade da cidade. Observou-se na pesquisa que a qualidade dos espaços livres, principalmente dos públicos, são os principais elementos de qualificação ou a requalificação das Unidades de Paisagem.

Durante a constatação do estado da arte sobre o conceito de Unidades de Paisagem, foram encontrados alguns exemplos da aplicação da metodologia, entretanto grande parte desses trabalhos não se atentava em apresentar o processo de aplicação metodológica, os critérios de identificação e delimitação das Unidades de Paisagem. Nesse sentido, o presente artigo buscou evidenciar os questionamentos e dificuldades da pesquisa, apontando cada passo que antecedeu a delimitação dessas unidades (mapas temáticos desenvolvidos), apresentando o exemplo de como uma das unidades foi catalogada.

A pesquisa pode auxiliar no processo de classificação e delimitação das Unidades de Paisagem de outras cidades, principalmente cidades de médio porte que possuem características semelhantes às encontradas em Patos de Minas. Além disso, o trabalho possibilita estudos comparativos capazes de evidenciar as diferentes aplicações da metodologia das U.P's nas diferentes configurações das cidades brasileiras.

O atual Zoneamentos Urbanos de Patos de Minas não reflete as características da paisagem local, pois áreas com características e necessidades distintas incorporam uma mesma zona: uma área com características de ruralidade ou com relações culturais e de subsistência com o rio ou córregos pode receber a mesma regulação urbanística que áreas mais adensadas, não refletindo as diferentes necessidades ambientais, econômicas e culturais da cidade? Apesar de regular o uso e a ocupação do solo, esse zoneamento não faz uma leitura das pré-existências dessa ocupação, como acontece na legislação de várias cidades brasileiras. Os possíveis desdobramentos 
desse trabalho são o desenvolvimento de políticas urbanas e projetos urbanísticos específicos, de acordo com a leitura de cada Unidade de Paisagem, buscando, assim, projetos que reflitam a identidade da cidade e suas reais necessidades sociais, estéticas, culturais e ambientais, objetivando uma cidade mais sustentável e prevenindo que a ocupação do solo ocorra de maneira equivocada, com conflitos de usos e degradação ambiental.

\section{Referências}

AMORIM, Nayara Cristina Rosa. O sistema de espaços livres na forma urbana de Patos de Minas. Dissertação de mestrado em Arquitetura e Urbanismo. Universidade Federal de Uberlândia. Uberlândia, 2015.

BERTRAND, G. Paisagem e geografia física global: esboço metodológico. Tradução: Olga Cruz. R RA'E GA, Curitiba: Editora UFPR, n. 8, p. 141-152, 2004.

CAMPOS, A. C. M. A. (Org.); QUEIROGA, E. F. (Org.); GALENDER, F. (Org.); DEGREAS, H. N. (Org.); AKAMINE, R. (Org.); MACEDO, S. S. (Org.); CUSTÓDIO, V. (Org.). Quadro dos sistemas de espaços livres nas cidades brasileiras. 1. ed. São Paulo: FAUUSP, 2012. v. 1.

CONAMA Resolução Nº 302 e 303/2002 - Dispõe sobre parâmetros, definições e limites de Áreas de Preservação Permanente. - Data da legislação: 20/03/2002 - Publicada no DOU no 90, de 13 de maio de 2002, Seção 1, págs. 67-68.

CONZEN, M. R. G. Alnwick, Northumberland: A Study in Town-Plan Analysis. In: Institute of British Geographers Publication n. 27. London: George Philip \& Son, 1960. Apud ROSANELI, Alessandro Filla. A morfologia urbana como abordagem metodológica para o estudo da forma e da paisagem de assentamentos urbanos, 2011.

DEL RIO, Vicente. Introdução ao desenho urbano no processo de planejamento. São Paulo: Editora Pini Ltda., 1990. $\begin{array}{llll}\text { GREGOTTI, Vittorio. } & \text { Território da } \\ \text { quitetura. } & \text { São } & \text { Paulo: } & \text { Perspectiva, }\end{array}$

IBGE Instituto Brasileiro de Geografia e Estatística. Disponível em: http://www.cidades.ibge.gov.br/ xtras/perfil.php? lang $=\& \operatorname{codmun}=314800 \&$ search $=m i$ nas-gerais|patos-de-minas. Acesso em: 01 abr. 2016.

LAMAS, JoséManuelRessano GarciaMorfologiaurbanaedesenho da cidade. $3^{\mathrm{a}}$ ed. Porto: Fundação Colouste Gulbenkian, 2004.

MAGNOLI, Miranda Martinelli. Espaços livres e urbanização. Tese (Livre-docência) São Paulo: FAUUSP, 1982.

MOUDON, Anne Vernez. Urban morphology as an emerging in- 
terdisciplinary field. Urban Morphology, v. 1, n. 1, p. 3-10, 1997. MOUDON, Anne Vernez. Getting to Know the Built Landscape: Typomorphology. In: FRANK, K. A. \& SCHNEEKLOTH (ed.). Ordering Space: Types in Architecture and Design, 1994.

NUCCl, João Carlos Qualidade ambiental e adensamento urbano. São Paulo: Humanitas/ FAPESP, 2001.

PATOS DE MINAS, Prefeitura Municipal. Mapas e dados fornecidos pelo setor de planejamento urbano, 2015.

RIBEIRO, Maria Eliana Jubé. Infraestrutura verde: uma estratégia de conexão entre pessoas e lugares. Por um planejamento urbano ecológico para Goiânia. Tese de doutorado em Arquitetura e Urbanismo. FAUUSP, São Paulo, 2010.

SANDEVILLE JUNIOR, Euler. Miranda Martinelli Magnoli: contribuição fundamental para uma teoria e ação do arquiteto na paisagem brasileira. Uma aproximação de seus escritos. Revista Paisagem e Ambiente, v. 21, p. 80-100, 2006.

SILVA, Jonathas Magalhães Pereira da. Unidade de paisagem e o estudo da forma urbana: reflexões sobre suas contribuições para o campo disciplinar da arquitetura e urbanismo. Campinas: [s.n.], 2012.

WHITEHAND, J. W. R. British urban morphology: the Conzenian tradition. In: Urban Morphology v. 5, n. 2, 2001, p. 103 $-109$.

Recebido em 05/07/2016

Aprovado em 16/12/2016 
Cadernos de Arquitetura e Urbanismo, v.23, n.33, 2" sem. 2016 